\title{
Reglas y normas editoriales
}

El objetivo del Boletín de Información sobre Recursos Genéticos Animales (AGRI) es la divulgación de la información sobre una mejor gestión de los recursos genéticos animales de interés para la producción alimentaria y agrícola, siguiendo la Estrategia Mundial para la Gestión de los Recursos Genéticos de los Animales Domésticos. Todos los aspectos referidos a la caracterización, la conservación y el uso de estos recursos serán tomados en consideración, de acuerdo con el Convenio sobre la diversidad biológica.

AGRI publicará información sobre genética, encuestas fenotípicas y económicas y descripciones comparativas, uso, desarrollo y conservación de los recursos genéticos animales, así como sobre el desarrollo de estrategias operacionales y normas que permitan una gestión más eficaz de la relación costo/eficacia. Por ello, AGRI prestará especial atención a las contribuciones referidas a razas y normas capaces de contribuir a la intensificación sostenible de los medios (agroecosistemas) con ingresos medios y bajos en el mundo, que comprenden casi la mayor parte de las tierras dedicadas a la producción ganadera; la producción total de alimentos y agricultura provenientes de la ganadería; y el resto de los recursos genéticos de animales domésticos.

Los puntos de vista expresados en los artículos publicados en AGRI son solamente las opiniones de los autores y, por tanto, no reflejan necesariamente la opinión de las instituciones para las cuales trabajan dichos autores, de la FAO o de los editores.

La oportunidad o no de publicar un artículo en AGRI será juzgada por los editores y revisores.

\section{Publicación electrónica}

Además de su publicación impresa, la versión íntegra de AGRI se encuentra disponible electrónicamente en Internet, en el sitio: www.fao.org/dad-is/

\section{Tipos de artículos}

Serán publicados en AGRI los siguientes tipos de artículos:

\section{Artículos sobre investigación}

Se tomarán en consideración para su publicación en AGRI los estudios sobre la caracterización, conservación y uso de los recursos genéticos de los animales domésticos (AnGR) con una buena descripción del entorno. Se agradecerá el envío de fotografías de calidad que presenten a las razas en cuestión en su ambiente natural de producción.

\section{Artículos de revisión}

Se podrán tomar en consideración ocasionalmente aquellos artículos que presenten una revisión de los agroecosistemas, a nivel nacional, regional o mundial, con el desarrollo de uno o más aspectos referidos a la gestión de los recursos genéticos animales, incluidas las revisiones sobre el estado actual de las distintas áreas de AnGR.

\section{Artículos específicos}

Se solicitarán puntualmente artículos sobre temas específicos para ediciones especiales.

\section{Otro material para publicación}

Incluye la revisión de libros, noticias y notas referidas a reuniones importantes, cursos de formación y principales eventos nacionales, regionales e internacionales, así como conclusiones y recomendaciones relacionadas con los objetivos de estos principales eventos. Se invita a los lectores a enviar este tipo de material a los editores.

\section{Guía para los autores}

\section{Presentación del manuscrito}

Los artículos se presentarán en inglés, francés o español, junto con un resumen en inglés y su traducción en francés o español, y se enviarán al editor de AGRI, AGAP, FAO, Viale delle Terme di Caracalla, 00153 Roma, Italia. El artículo deberá ser enviado en versión WinWord en fichero adjunto por correo electrónico a agribulletin@fao.org. Las fotografías, color o en blanco y negro, se enviarán siempre por correo normal.

Los manuscritos se presentarán con doble espacio y con el número correspondiente a cada línea en el margen izquierdo. Todas las páginas serán numeradas, incluidas las de las referencias bibliográficas, cuadros, etc. El autor recibirá una notificación sobre la recepción de su documento.

En el caso de aceptación de un artículo después de su revisión, se solicitará al autor una versión final de su artículo revisado en disquete (formato 31/2") en Word $6.0 \times$ Windows, así como una copia impresa del mismo.

\section{Preparación del manuscrito}

En la primera página del manuscrito se indicará el título abreviado del artículo, títulos y nombres de los autores, instituciones, direcciones completas (incluido código postal y número de teléfono); así como otros medios de contacto tales como fax, correo electrónico, etc. del autor principal. El título abreviado no deberá sobrepasar los 45 caracteres más los espacios correspondientes, y aparecerá en la parte 
superior de la página 1 del manuscrito en mayúsculas. El título entero del manuscrito se escibirá en mayúsculas y minúsculas. Dicho título debe ser lo más breve posible y no sobrepasar los 150 caracteres (incluidos los espacios necesarios), con los nombres de las especies, si necesario. Los nombres de los autores, instituciones y direcciones se escribirán en cursiva y en letras mayúsculas y minúsculas. Se dejará una línea en blanco entre el título y los nombres de los autores. Las direcciones se escribirán como notas de pie de página de cada autor después de dejar una línea en blanco entre los nombres y éstas. Cada nota de pie de página con la dirección será indicada numéricamente. Se dejarán dos líneas en blanco después de las direcciones.

\section{Títulos}

Los títulos de cada sección, por ejemplo Resumen, Introducción, etc., serán alineados a la izquierda. Dejar dos líneas en blanco entre las notas de pie de página con las direcciones y el Resumen y entre el título Resumen y el texto que sigue. El resumen no deberá exceder de 200 palabras. Deberá ser un resumen objetivo que describa brevemente los procesos y logros obtenidos, y no una presentación de cómo se ha llevado a cabo el estudio y una descripción genérica de los resultados. Dejar una línea en blanco entre el final del texto del resumen y las palabras clave, que se escribirán en cursiva así como el titulo Palabras clave. No deberán ser más de seis y no deberán contener "y" o "\&". Todos los títulos principales de capítulo (14 regular) y subcapítulo (12 regular) serán en negrita e irán precedidos y seguidos de una línea en blanco. El texto correspondiente empezará sin sangrado. Un título dentro de un subcapítulo se escribirá en cursiva e irá seguido de un punto con a continuación el texto correspondiente.

\section{Cuadros y figuras}

Los cuadros y las figuras se incluirán al final del texto siguiendo el orden de cita dentro del mismo. Las fotografías no serán devueltas a sus autores.

\section{Cuadros}

Los cuadros, incluidas las notas de pie de página, deberán ir precedidos y seguidos por dos líneas en blanco. El número del cuadro y su título se escribirán en la parte superior en cursiva (12) con un punto al final y seguido de una línea en blanco. En cada columna o título de encabezamiento o subtítulo, sólo la primera letra de la primera palabra irá en mayúscula. Los cuadros irán numerados de forma consecutiva con números árabes. Los cuadros y sus títulos se alinearán a la izquierda, así como el texto. Se utilizarán líneas horizontales o verticales sólo cuando sea necesario. No utilizar tabuladores o la barra espaciadora para crear un cuadro.

\section{Figuras}

Las figuras, incluidos los títulos y leyendas, irán precedidas y seguidas de dos líneas en blanco. El número de la figura y el título se escribirán en la parte superior en cursiva (12) con un punto al final. La palabra figura incluye las fotografías, los gráficos, los mapas, los diagramas, etc. En el caso del diagrama se enviará la matriz original con los datos utilizados para crearlo. Se recomienda encarecidamente la utilización de Word 6.0 o Excel 5.0 para la presentación de los diagramas.

\section{Referencias}

Toda referencia presente en el texto deberá aparecer en la lista de referencias y, de la misma manera, cada referencia de la lista deberá haber sido citada por lo menos una vez en el texto. Las referencias deben ir en orden alfabético del apellido del autor, seguido por el año.

- Ejemplo en el caso de una referencia de una revista: Köhler-Rollefson, I. 1992. The camel breeds of India in social and historical perspective. Animal Genetic Resources Information 10, 53-64.

- Cuando se trate de más de un autor: Matos, C.A.P., D.L. Thomas, D. Gianola, R.J. Tempelman \& L.D. Young. 1997. Genetic analysis of discrete reproductive traits in sheep using linear and nonnlinear models: 1. Estimation of genetic parameters 75, 76-87.

- En el caso de un libro o de una publicación ad hoc, por ejemplo informes, tesis, etc.: Cockrill, W.R. (Ed.). 1994. The Husbandry and Health of the Domestic Buffalo. FAO, Rome, Italy, pp. 993.

- Cuando se trate de un artículo dentro de las actas de una reunión: Hammond, K. 1996. FAO's programme for the management of farm animal genetic resources. In C. Devendra (Ed.), Proceedings of IGA/FAO Round Table on the Global Management of Small Ruminant Genetic Resources, Beijing, May 1996, FAO, Bangkok, Thailand, 4-13.

- Cuando la información contenida en el artículo haya sido obtenida o derive de un sitio World Wide Web, poner el texto entre comillas; por ejemplo "sacado de la FAO. 1996" e indicar en las Referencias la forma estándar URL: FAO. 1996. Domestic Animal Diversity Information System, http://www.fao.org/dad-is/, FAO, Rome, Italy.

Se ruega enviar los manuscritos o la correspondencia relativa a AGRI a la dirección siguiente:

agri-bulletin@fao.org

Gracias por su colaboración 